\title{
Impact of the Superpave hot mix asphalt properties on its permanent deformation behavior
}

\author{
Zahra Qasim ${ }^{1}$, Alaa Abed ${ }^{2}$, and Zaynab Qasim ${ }^{3, *}$ \\ ${ }^{1}$ University of Baghdad, Baghdad, Iraq \\ ${ }^{2}$ University of Al-Nahrain, Bagdad, Iraq \\ ${ }^{3}$ University of Technology, Baghdad, Iraq
}

\begin{abstract}
In Iraq, the severity of rutting has increased in asphalt pavements possibly due to the increase in truck axle loads, tyre pressure, and high pavement temperature in summer. As of late, Superpave has been accounted as an enhanced system for performance based design, analysis of asphalt pavement performance prediction for asphalt concrete mixes. In this research the development of permanent deformation in asphalt concrete under repeated loadings was investigated, Wheel-Tracking apparatus has been used in a factorial testing program during which 44 slab samples were tested to simulate actual pavement. The objectives of the present research include; investigating the main factors affecting rutting in asphalt concrete mixture, quantifying the effect of SBS polymer and steel reinforcement on asphalt concrete mixtures in addition to studying the effect of variables on the asphalt concrete mixes against moisture sensitivity. It has been determined that that increasing of compaction temperature from 110 to $150{ }^{\circ} \mathrm{C}$ will decrease the permanent deformation by 20.5 and 15.6 percent for coarse and fine gradation control asphalt mixtures, respectively. While the permanent deformation decreases by 21.3 percent when the compaction temperature is increased from 110 to $150{ }^{\circ} \mathrm{C}$ for coarse gradation SBS modified asphalt mixtures.
\end{abstract}

\section{Introduction}

Rutting is the major distress in flexible pavements in Iraq as a result of increasing axle loads, and high summer temperature, [1]. Rutting reduces the useful service life of the pavement. By affecting vehicle handling characteristics, it creates serious hazards for highway users; the gradual effects of weathering and the action of vehicle traffic are the two major elements contribute to asphalt pavement deterioration as sited by [2].

Rutting has been a major concern for flexible asphalt pavement. It is also one of the most common pavement permanent deformations due to repetitive traffic loads which accumulate small deformations of pavement materials appearing as longitudinal depressions in the wheel paths of the roadways.

Early detection and repair of pavement defects is the most important preventive maintenance procedure. There are five areas of distress for which guidance is needed: fatigue cracking, (wheel path) rutting, thermal cracking, friction, and moisture susceptibility, all of these distresses can result in loss of performance, but rutting or permanent deformation is the one distress that is most likely to be a sudden failure as a result of unsatisfactory hot mix asphalt or asphalt mixture, other distresses are typically long term failures that show up after a few years of traffic [3].
Up-to-date, Superpave has been widely known as an improved system for perform based design, Investigation about asphalt concrete mixes and asphalt pavement performance prediction. It will be an organized methodology comprising of choice for materials, determination for design aggregate structure, asphalt binder content, and evaluation of moisture sensitivity.

In Iraq, the severity of rutting has been increased in asphalt pavements possibility due to the increase in track axle loads, tyre pressure; and high pavement temperature during summer, [4].

\section{Research objectives}

The main objectives of this study is to investigate the main factors affecting rutting in asphalt concrete mixture in Iraq such as; mix properties, types of filler, loading and temperature conditions by using superpave mix design system, investigate the effect of additive (SBS) on the asphalt concrete mixes improvement and quantify the effect of steel reinforcement in asphalt concrete slabs using Wheel-Tracker testing.

\section{Materials properties}

The materials used in this research are widely available and currently used in road paving in Iraq except steel reinforcement which is brought from local market. 


\subsection{Binder}

The binder used in this research is classified as (40-50) penetration grade or PG (64-16) performance grade; it is brought from Daurah Refinery in Baghdad. Table 1 shows the physical properties of the used Asphalt Cement.

\subsection{Aggregate}

The (crushed) aggregate used in this study is brought from Al-Nibaie quarry. The physical properties and chemical composition of the aggregate (coarse and fine) are shown in Table 2 and 3. Two types of mineral filler are used: limestone dust brought from the lime factory in Karbala governorate and Portland cement is from factory of Kubesa in Iraq. It is thoroughly dry and free from aggregations of fine particles or lumps.

Table 1. Properties of asphalt cement, according to ASTM requirement and Iraqi specifications.

\begin{tabular}{|c|c|c|c|}
\hline Test & $\begin{array}{c}\text { ASTM } \\
\text { Designation }\end{array}$ & $\begin{array}{c}\text { Test } \\
\text { Results }\end{array}$ & $\begin{array}{c}\text { SCRB/ } \\
\text { R9 } \\
2003 \\
\end{array}$ \\
\hline $\begin{array}{l}\text { Penetration, }(100 \mathrm{gm}, \\
25^{\circ} \mathrm{C}, 5 \text { sec., }(0.1 \mathrm{~mm})\end{array}$ & D-5 & 45 & $40-50$ \\
\hline $\begin{array}{l}\text { Ductility }\left(25^{\circ} \mathrm{C},\right. \\
5 \mathrm{~cm} / \mathrm{min}), \mathrm{cm}\end{array}$ & D-113 & $>100$ & $>100$ \\
\hline Flash Point, ${ }^{\circ} \mathrm{C}$ & D-92 & 289 & $\begin{array}{l}\text { Min. } \\
232\end{array}$ \\
\hline $\begin{array}{l}\text { Specific Gravity } \\
\qquad\left(25^{\circ} \mathrm{C}\right)\end{array}$ & D-70 & 1.043 & $\cdots \cdots$ \\
\hline \multicolumn{4}{|c|}{ Residue from thin film oven test, D-1754 } \\
\hline $\begin{array}{c}\text { \%Retained } \\
\text { Penetration, } 1 / 10 \mathrm{~mm} \\
\end{array}$ & D-5 & 67.4 & $>55 \%$ \\
\hline Mass Loss, $\%$ & D-1754 & 0.38 & $<0.75$ \\
\hline $\begin{array}{l}\text { Ductility of } \\
\text { Residue, cm }\end{array}$ & D-113 & $>100$ & $>25$ \\
\hline
\end{tabular}

Table 2. The Physical properties of al-Nibaie aggregate

\begin{tabular}{|l|c|c|c|}
\hline \multicolumn{1}{|c|}{ Test } & $\begin{array}{c}\text { ASTM } \\
\text { desig. }\end{array}$ & $\begin{array}{c}\text { Test } \\
\text { result }\end{array}$ & $\begin{array}{c}\text { Superpave } \\
\text { Specificatio } \\
\text { n }\end{array}$ \\
\hline $\begin{array}{l}\text { Superpave coarse } \\
\text { aggregate angularity, } \\
\%\end{array}$ & $\begin{array}{c}\text { ASTM } \\
\text { D-5821 }\end{array}$ & 97 & $90 / 95$ Min \\
\hline $\begin{array}{l}\text { Fine aggregate } \\
\text { angularity, \% }\end{array}$ & T-304 & 61 & 45 Min. \\
\hline $\begin{array}{l}\text { Percent flat and } \\
\text { elongated } \\
\text { particles, \% }\end{array}$ & $\begin{array}{c}\text { ASTM } \\
\text { D-4791 }\end{array}$ & 1.6 & $10 \%$ Max. \\
\hline $\begin{array}{l}\text { Clay content by } \\
\text { Sand equivalent, } \%\end{array}$ & T-176 & 51 & 45 Min. \\
\hline $\begin{array}{l}\text { Toughness, by (Los } \\
\text { Angeles Abrasion) }\end{array}$ & T-96 & 15.2 & $35-45$ Max. \\
\hline $\begin{array}{l}\text { Soundness loss by } \\
\text { sodium sulfate } \\
\text { solution,\% }\end{array}$ & T-104 & 2.46 & $10-20$ Max. \\
\hline $\begin{array}{l}\text { Deleterious } \\
\text { materials, \% }\end{array}$ & T-112 & 0.5 & $0.2-10$ Max. \\
\hline
\end{tabular}

Table 3. Chemical composition of al-Nibaie aggregates

\begin{tabular}{|c|c|}
\hline Chemical Compound & Content, \% \\
\hline Silica, Sio2 & 84.73 \\
\hline Lime, $\mathrm{CaO}$ & 3.37 \\
\hline Magnwasia, MgO & 0.53 \\
\hline $\begin{array}{c}\text { Sulphuric Anhydride, } \\
\text { SO }\end{array}$ & 2.9 \\
\hline Alumina, AlO & 0.62 \\
\hline Ferric Oxide, FeO & 0.58 \\
\hline Loss on Ignition & 6.25 \\
\hline Total 98.98 & 98.98 \\
\hline \multicolumn{2}{|c|}{ Mineral composition } \\
\hline Quartz & 81.2 \\
\hline Calcite & 10.02 \\
\hline
\end{tabular}

Two types of aggregate gradation have been used in this research as shown in Table 4, The aggregate is sieved and recombined in the satisfactory proportions to declaration the gradation of wearing course as headed by SCRB specifications [5]. The aggregate maximum size gradation of $19 \mathrm{~mm}$ is used in this study. The aggregate fractions are separated into nine sizes using dry sieve analysis. Mineral filler (Limestone and Portland cement) are added according to requirements of desired gradation. Figure 1 shows the gradation curve for the aggregate. Four lines are presented: the lower, the upper curves of the Iraqi specifications of SCRB in addition to the control points according to Superpave system.

Table 4. The selected aggregate gradations as a percent passing by weight

\begin{tabular}{|c|c|c|c|c|}
\hline \multirow{2}{*}{ Sieve Size } & \multicolumn{2}{|c|}{$\begin{array}{c}\text { Gradation } \\
\text { \% Passing }\end{array}$} & \multicolumn{2}{c|}{$\begin{array}{c}\text { Iraqi Specification } \\
\text { SCRB,R9, 2003 }\end{array}$} \\
\hline$(\mathrm{mm})$ & $\begin{array}{c}\text { Coarse } \\
\text { Blend }\end{array}$ & $\begin{array}{c}\text { Fine } \\
\text { Blend }\end{array}$ & Max. & Min. \\
\hline 19 & 100 & 100 & 100 & 100 \\
\hline 12.5 & 98 & 92 & 100 & 90 \\
\hline 9.5 & 88 & 78 & 90 & 76 \\
\hline 4.75 & 67 & 48 & 74 & 44 \\
\hline 2.36 & 47 & 32 & 58 & 28 \\
\hline 1.18 & 23 & 16 & --- & -- \\
\hline 0.6 & 15 & 12 & --- & -- \\
\hline 0.3 & 17 & 8 & 21 & 5 \\
\hline 0.075 & 5 & 5 & 10 & 4 \\
\hline
\end{tabular}




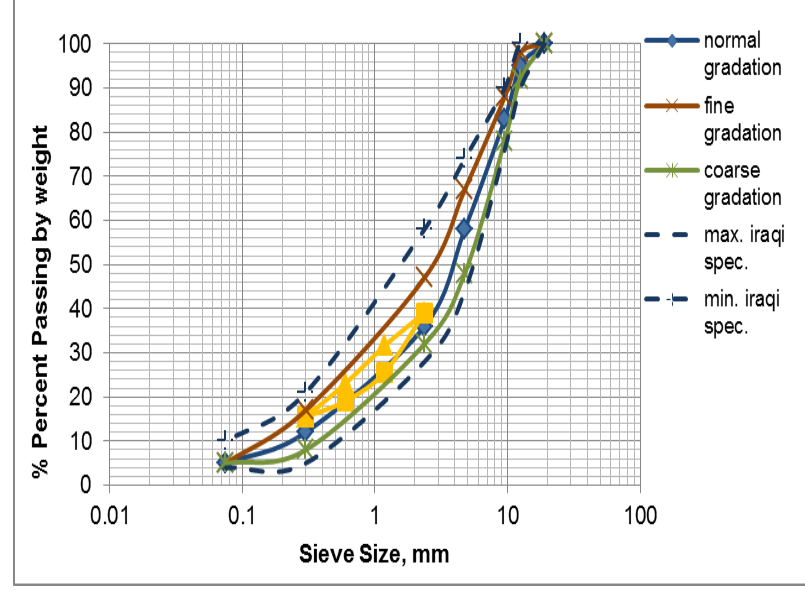

Fig. 1. Selected gradation for used aggregated

\subsection{Additives}

One type of polymer has been used in this research as an additive to the asphalt binder. The additive is known as SBS polymer (Styrene Butadiene Styrene), it's widely accepted asphalt binder modification agent used by the whole bitumen industries. 3\% SBS is added by weight of asphalt binder.

Improvement in fatigue damage, thermal cracking, rutting resistance, temperature susceptibility, and stripping have led SBS polymer modified binders to be a substitute for non-modified, neat bitumen in many paving and maintenance applications. Table 5 shows the physical properties of modified binder.

Table 5. Properties of modified binder

\begin{tabular}{|c|c|c|c|}
\hline Test & $\begin{array}{c}\text { Original } \\
\mathbf{4 0 - 5 0}\end{array}$ & $\begin{array}{c}\text { Modified } \\
+\mathbf{3} \% \text { SBS }\end{array}$ & $\begin{array}{c}\text { SCRB/R9 } \\
\mathbf{2 0 0 3}\end{array}$ \\
\hline $\begin{array}{c}\text { Penetration, } \\
\left(\begin{array}{c}\text { (100gm, } 25^{\circ} \mathrm{C}, 5 \mathrm{sec} ., \\
(0.1 \mathrm{~mm}))\end{array}\right.\end{array}$ & 45 & 68 & $40-50$ \\
\hline $\begin{array}{c}\text { Ductility }\left(25^{\circ} \mathrm{C},\right. \\
5 \mathrm{~cm} / \mathrm{min}), \mathrm{cm}\end{array}$ & $>100$ & $>200$ & $>100$ \\
\hline $\begin{array}{c}\text { Flash Point, }{ }^{\circ} \mathrm{C} \\
\text { Residue from thin film oven test, D-1754 }\end{array}$ & 289 & 300 & Min.232 \\
\hline $\begin{array}{c}\text { \% Retained } \\
\text { Penetration, } 1 / 10 \\
\text { mm }\end{array}$ & 67.4 & 50 & $>55 \%$ \\
\hline $\begin{array}{c}\text { Mass Loss, \% } \\
\text { Ductility of } \\
\text { Residue, cm }\end{array}$ & 0.38 & 0.36 & $<0.75$ \\
\hline
\end{tabular}

\subsection{Mesh steel reinforcement}

Configuration of the Mesh Steel Reinforcement used in this research consists of diamond shaped hole of size 40 by 30 by $1 \mathrm{~mm}$, as shown in Figure 2. This mesh is protected against corrosion by a zinc coating. These meshes are available in local market and proposed to be used in this research as a reinforcement interlayer.

As a part of the experimental work, forty-four asphalt slab samples, with and without mesh steel reinforcement were prepared and tested in the laboratory. The reinforcement were cut and placed in the middle of asphaltic mixtures in the rectangular mold of the Roller Compacter machine with dimensions of $300 \mathrm{~mm}$ by 400 $\mathrm{mm}$.

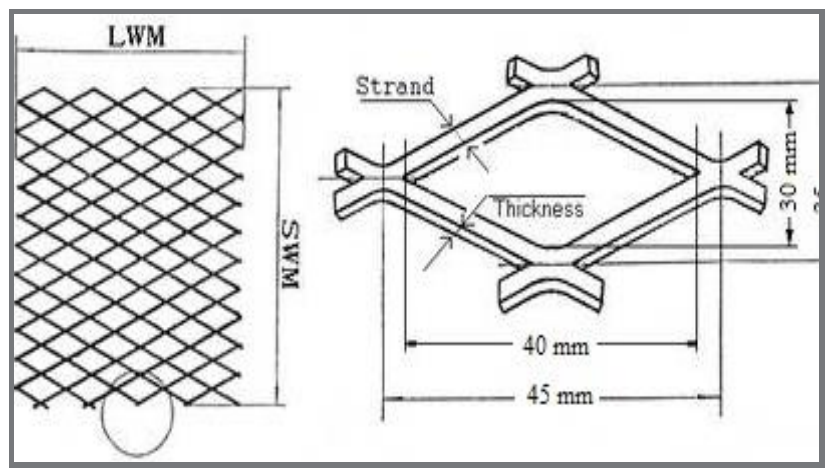

Fig.2. Configuration of mesh steel reinforcement

\section{Mix design}

In this research the volumetric properties of the HMA were found in accordance with Superpave Volumetric Mix Design (AASHTO M-323), [6]. Obviously, the design air voids (4\%) for all Superpave mixes meet the specifications for percent air voids, [7]. Optimum binder content for different mixtures of the surface layer is determined using Superpave method. Four mixtures were tested to determine the optimum asphalt content: two gradations (coarse and fine gradation) and with two types of asphalt (origin and modified asphalt with SBS polymer). The Superpave Gyratory Compactor was used to prepare 24 cylindrical specimens of asphalt concrete for carrying out volumetric design according to Superpave system (AASHTO Designation: T 312-2010). Specimens were prepared by mixing at the appropriate mixing temperature, which is $160^{\circ} \mathrm{C}$ for the selected asphalt binder PG (64-16) and $180^{\circ} \mathrm{C}$ for modified asphalt binder. The specimens were then short-term aged by placing the loose mix in a flat pan in a forced draft oven at the compaction temperature $148^{\circ} \mathrm{C}$ and $165^{\circ} \mathrm{C}$, for 2 hours for origin and modified asphalt respectively. Finally, the specimens were then removed and either compacted or allowed to cool loose (for Gmm determination).

\section{Evaluation of moisture susceptibility}

Moisture damage in reality can be defined as the loss of strength and durability in asphaltic mixtures caused by the presence of water, [8]. Moisture damage is induced by the loss of bond between the asphalt cement or the mastic (asphalt cement, the mineral filler and small aggregates) and the coarse and fine aggregate. Moisture damage accelerates as moisture permeates and weakens 
the mastic, making it more susceptible to moisture during cyclic loading. For evaluating the moisture damage in asphalt concrete, specimens with dimensions of $(150 \mathrm{~mm})(6 ")$ in diameter and $(95 \mathrm{~mm})\left(3.8^{\prime \prime}\right)$ height for Superpave asphalt design mixes are used. Specimens are prepared according to AASHTO $\mathrm{T}$ 283-07, left to cool at room temperature for 24 hours. The number of desired gyrations is determined to obtain test specimens with approximately 7 percent \pm 1 of air voids using different number of gyrations that is $(75) \pm 3$ for asphalt coarse gradation mixtures, as shown in Figure 3.

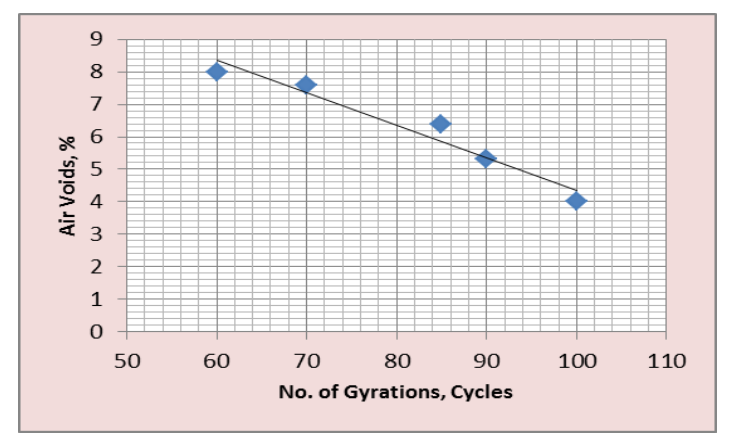

Fig.3. Relation between no. of gyrations and air void percentage

Eight subset of test specimen are produced in this research. Specimens are compacted in Superpave Gyratory Compactor to a specimen height of $95 \mathrm{~mm}$ with air void content approximately seven percent as presented in Figure 4. Each subset containing six specimens prepared for each mix with optimum asphalt content.

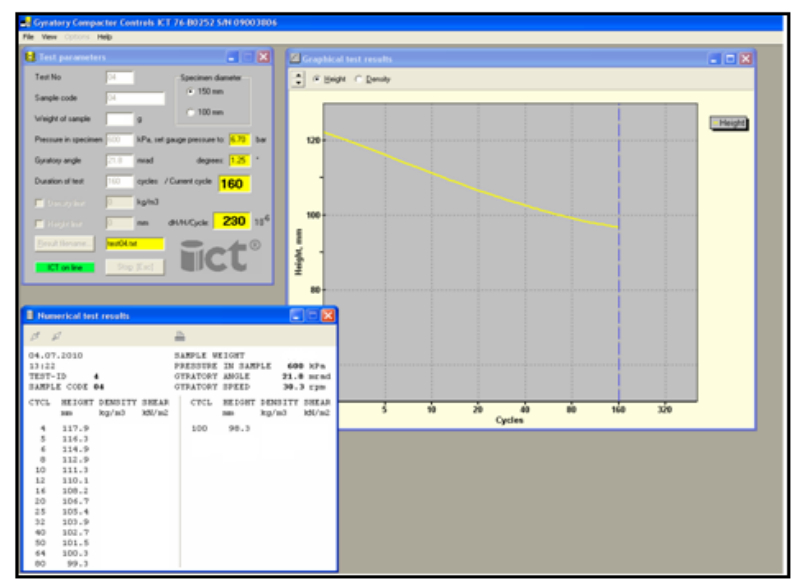

Fig. 4. Moisture susceptibility test by superpave gyratory compactor

Six specimens (three conditioned and three unconditioned specimens) are tested by Versa Tester Machine, as shown in Figure (5) at a rate of (50.8 $\mathrm{mm} / \mathrm{min}$.) (2"/min.) until the maximum load is reached and the specimen completely fractures then the load is recorded. Indirect Tensile Stress is calculated as follows:

$$
S t=2 P / \pi t D
$$

where: $\mathrm{St}=$ tensile strength, $\mathrm{kPa}(\mathrm{psi}) ; \mathrm{P}=$ maximum load, N (lbf);

$\mathrm{t}=$ specimen height immediately before tensile test, $\mathrm{mm}$ (in); $\mathrm{D}=$ specimen diameter, $\mathrm{mm}$ (in.).

Then the Tensile Strength Ratio is calculated as follows:

$$
T S R=\left(S_{t m} / S_{t d}\right) * 100
$$

Where: $\mathrm{TSR}=$ tensile strength ratio in percent; $\mathrm{S}_{\mathrm{tm}}=$ average tensile strength of the moisture conditioned subset, $\mathrm{kPa}$; and $\mathrm{S}_{\mathrm{td}}=$ average tensile strength of the dry subset, $\mathrm{kPa}$.

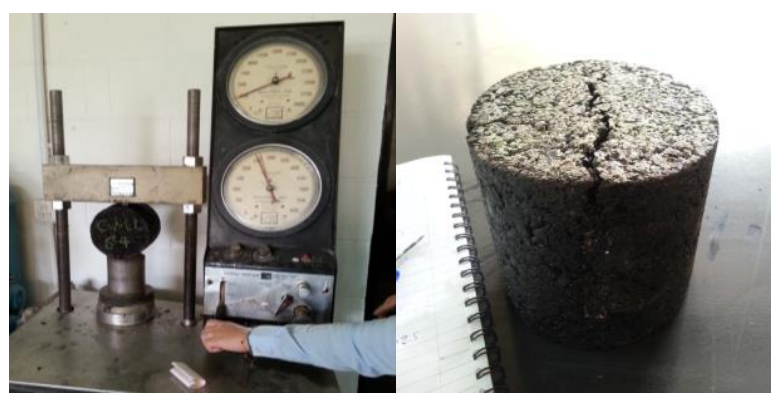

Fig. 5. Indirect tensile test device

\section{Sample preparation}

The roller compacter apparatus can compact asphalt slabs to a target density using loads per unit roll width, which are consistent to those of pavement rollers used in the highway construction. The roller compactor provides a pneumatically powered means of compacting slabs of asphaltic material in the laboratory under conditions, which simulate in-situ compaction, as shown in Figure 6.

In this research, compacted asphaltic slabs for rutting test are prepared at air voids equal to (4\%) using Roller Compactor Device according to (EN12697-Part 33:2003) and Superpave system (AASHTO Designation: T312-2010). The dimensions of the compacted slabs used in this work are of (400 $\mathrm{mm}$ by $300 \mathrm{~mm}$ by $50 \pm 6$ $\mathrm{mm}$ ) as proposed by (EN 12697-Part 22:2003)[9].

Proportion of aggregate and asphalt binder are used for mixing, curing, and compacting. The fractions of aggregate are separated into 9 sizes, as retained on each of the following sieves, 3/4", 1/2", 3/8", No.4, No.8, No.16, No.30, No.50, and No.200) using dry sieve analysis. The aggregate retained on the $3 / 4 "$ sieve is discarded. Mineral filler (Limestone) and cement have been added according to the desired gradations requirements. The aggregate is combined into batch of (13400 gm for slab specimen) on the mixing bowl and heated to the mixing temperatures prior to mixing with asphalt binder which heated to the mixing temperatures corresponding to each binder.

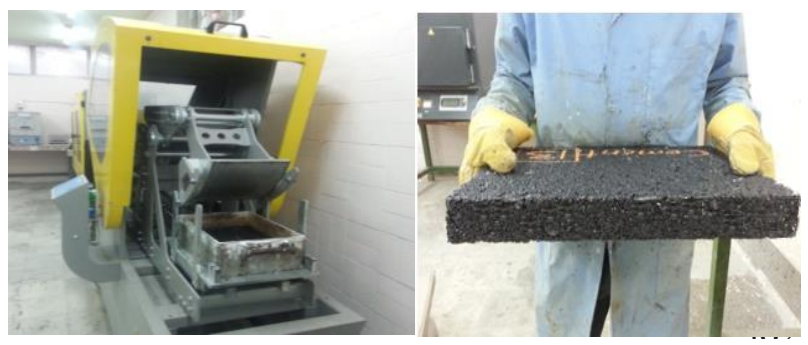


Fig. 6. Compacted slab by roller wheel compactor machine

\section{Wheel-tracking testing}

The Wheel Tracker of pavement is a device used for testing the asphalt mixes wearability by simulating roadway conditions, this test was performed according to EN 12697-22:2003 [9] and AASHTO Designation: T 340-10. The test provides information about the rate of permanent deformation from a moving the sample under concentrated load. It uses a Linear Value Displacement Transducer (LVDT's) to measure the deformation or rutting of the specimen. The loaded wheel applies about $700 \mathrm{~N}$ (158 pounds) of load at contact points and passes repetitively over the asphaltic sample for up to 10,000 cycles.

Wheel-tracking machine is constructed so as to enable the test specimen in its cradle to be moved backwards and forwards under the loaded wheel in a fixed horizontal plane. The centre-line of the tyre track is $(5 \mathrm{~mm})$ from the theoretical centre of the specimen. The centre of the contact area of the tyre describes a simple harmonic motion with respect to the centre of the top surface of the test specimen with a total distance of travel of $(230 \pm 10) \mathrm{mm}$ and a constant loading frequency of $(26.5 \pm 1.0)$ load cycles per 60 seconds for the test device in approximately 10,000 load cycles or $20 \mathrm{~mm}$ maximum allowed deformation is reached.

The experiment design for the permanent deformation testing is a full factorial with; two asphalt contents, three compaction temperatures, two asphalt types: original and modified with SBS, with and without mesh steel reinforcement, and two types of gradations, resulting in a nominal total of 44 slab tests.

The compacted specimens, which are $30 \mathrm{~cm}$ in width, $40 \mathrm{~cm}$ in length and $5 \mathrm{~cm}$ in height, are cooled to room temperature for a period of 24 hours in accordance with (EN-12697-22). The specimens are placed in mold and then placed on the carriage table of WTD for testing. The specimens in the mold are labelled with information mix type.

The holder of the displacement transducer is disengaged and reference plate is adjusted such that the transducer probe is compressed approximately $70 \%$ of its total travel. This allowed having sufficient travel available to measure the track formation on the sample. If the maximum allowed deformation is reached before 10,000 passes, the wheel is lifted off the failed sample. Test results are compiled in a Microsoft Access database application which provides several means of reporting results, as shown in Figure 7.

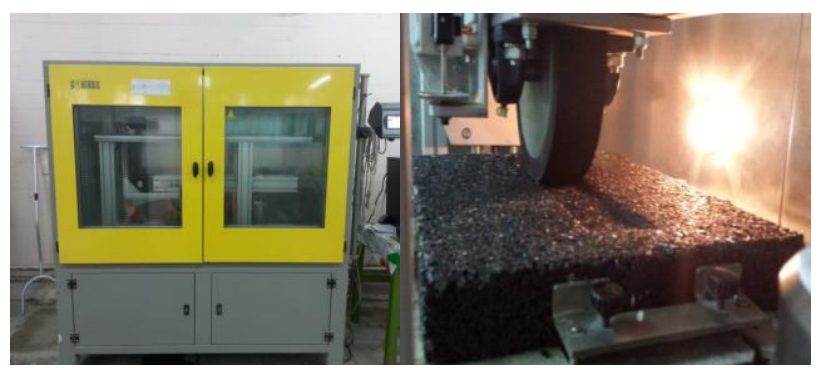

Fig.7. Wheel-tracking device and tested Sample

\section{Results and analysis}

Permanent deformation and vertical permanent strain (cp) were measured at testing temperature of $40{ }^{\circ} \mathrm{C}$, frequency level 53 passes per minute, two compaction temperatures of $110{ }^{\circ} \mathrm{C}$ and $150{ }^{\circ} \mathrm{C}$, two asphalt contents, two types of gradation, two types of filler, with and without mesh steel reinforcement and SBS polymer was used as modifier to asphalt binder.

\subsection{Effect of compaction temperature}

This study investigates the influence of compaction temperature on coarse and fine asphalt mixes for modified and unmodified binders.

For this, Superpave mix designs for two compaction temperatures of $110{ }^{\circ} \mathrm{C}$ and $150{ }^{\circ} \mathrm{C}$ and two asphalt binders (control, 3\% styrene butadiene styrene (SBS) modified) were carried out. A total of 44 specimens were manufactured with a short-term age for two hours at the mixture compaction temperatures prior to test.

Figure (8) shows effect of compaction temperature on Permanent deformation (i.e. rut depth, RD). It can be seen that permanent deformation decreases when compaction temperature changes from 110 to $150{ }^{\circ} \mathrm{C}$ as shown in Table (6). It can be observed that the rut depth (RD) decreases about 20.5 and 15.6 percent when the compaction temperature increases from 110 to $150{ }^{\circ} \mathrm{C}$ for coarse and fine gradation control asphalt mixtures respectively. While the rut depth (RD) decreases about 21.3 percent when the compaction temperature increases from 110 to $150{ }^{\circ} \mathrm{C}$ for coarse gradation SBS modified asphalt mixtures as shown in Figure 9.

The results from this study showed that the compaction temperatures significantly affected the volumetric properties of the SBS modified mixes. The mixtures containing SBS-modified binders, the rut depth decreased by 21.3 percent and the air-void contents significantly decreased with an increase in compaction temperature because the binder in modified asphalt mixtures is stiffer than in conventional mixtures; therefore, there is a need for a higher compaction temperature.

Table 6. Percentage of change in permanent deformation with compaction temperature

\begin{tabular}{|c|c|c|}
\hline \multirow{2}{*}{ Rut Depth , mm } & \multicolumn{2}{|c|}{$\begin{array}{c}\text { Effect of Temperature, } \\
\mathbf{1 1 0}^{\circ} \text { to } \mathbf{1 5 0} \text { 'C (\%) }\end{array}$} \\
\cline { 2 - 3 } & $\begin{array}{c}\text { Coarse } \\
\text { gradation }\end{array}$ & $\begin{array}{c}\text { Fine } \\
\text { gradation }\end{array}$ \\
\hline Control asphalt Mixtures & -20.5 & -15.6 \\
\hline Modified asphalt Mixtures & -21.3 & - \\
\hline
\end{tabular}




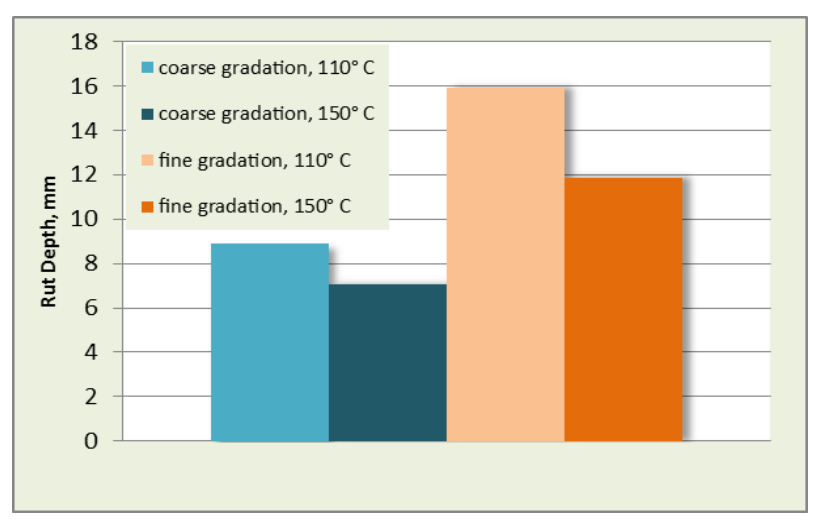

Fig. 8. Effect of compaction temperature of control mixtures on permanent deformation

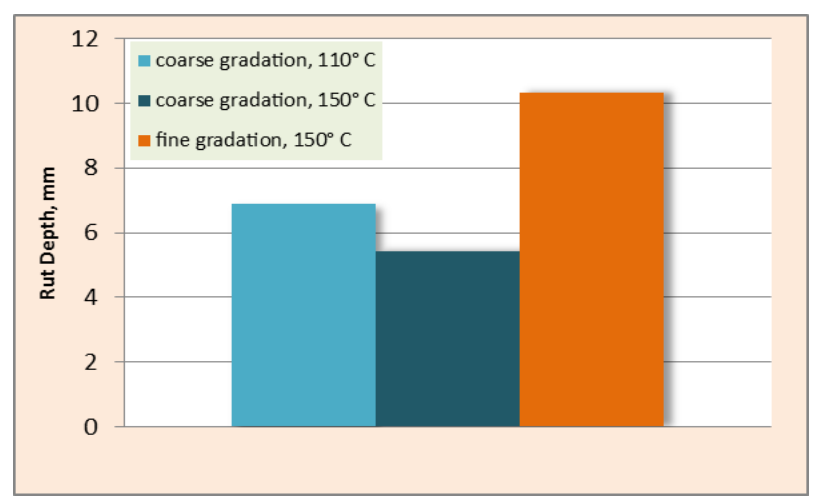

Fig. 9. Effect of compaction temperature on permanent deformation of modified mixtures

\subsection{Effect of asphalt / binder content}

Based on the data shown in Figures (10) to (12), it appears that the examined asphalt content has influence on the plastic response of the material. The plastic strain is increased with the increases in asphalt content from optimum $\mathrm{AC}$ to opt. +0.5 percent asphalt content for conventional and modified asphaltic mixtures. For (RD) value, it can be found that it increases about 10.6 percent when asphalt content increases from 4.6 to 5.1 percent for conventional coarse asphalt mixture, while it increases about 8 percent when asphalt content from 4.9 to 5.4 percent for SBS modified asphalt mixture, as shown in Table (7).

It can be concluded for Superpave mixtures, the total asphalt content plays an important significant role in controlling overall rutting resistance of the conventional and modified asphaltic mixtures, i.e rutting performance is highly influenced by total asphalt content, voids in mineral aggregate (VMA), voids filled with asphalt, (VFA), and dust-to-binder ratio.

Table 7. Percentage of change in permanent deformation with original asphalt content

\begin{tabular}{|c|c|c|}
\hline \multirow{2}{*}{ Variable } & Original Asphalt & Modified Asphalt \\
\cline { 2 - 3 } & $4.6 \%$ to $5.1 \%$ & $4.9 \%$ to $5.4 \%$ \\
\hline
\end{tabular}

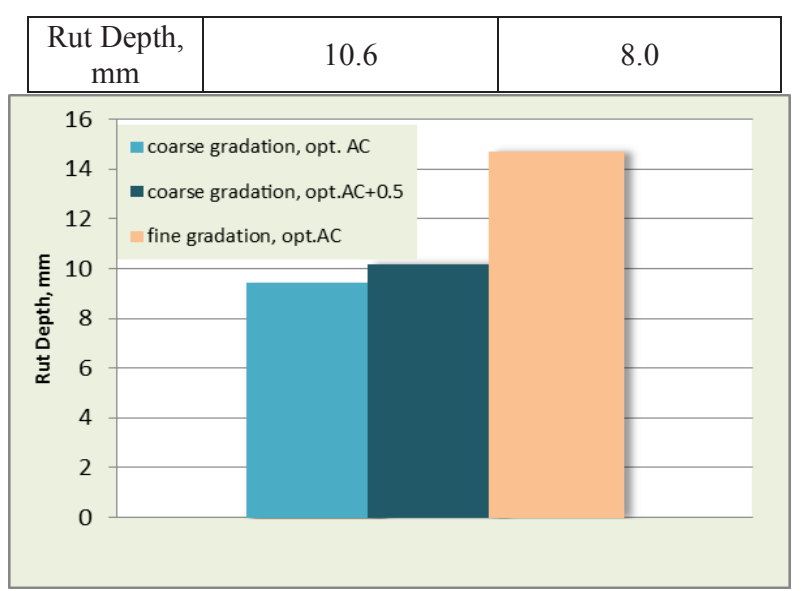

Fig.10. Effect of asphalt content of conventional mixture on Permanent deformation

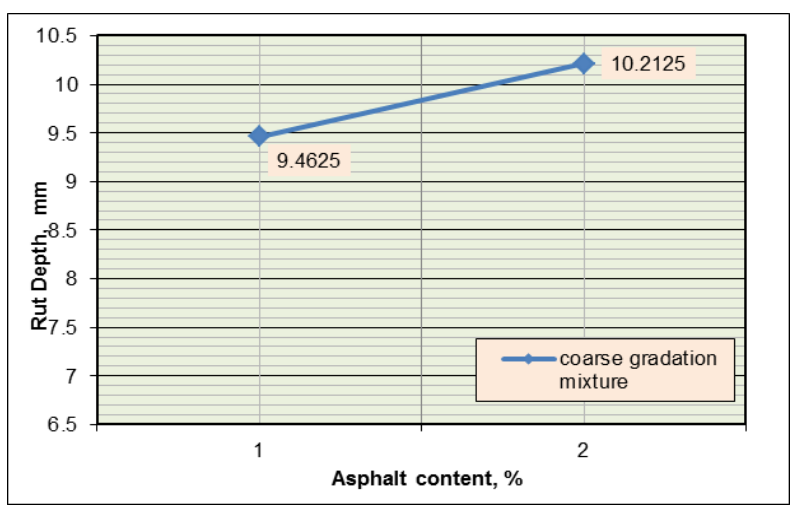

Fig. 11. Change in permanent deformation with asphalt content

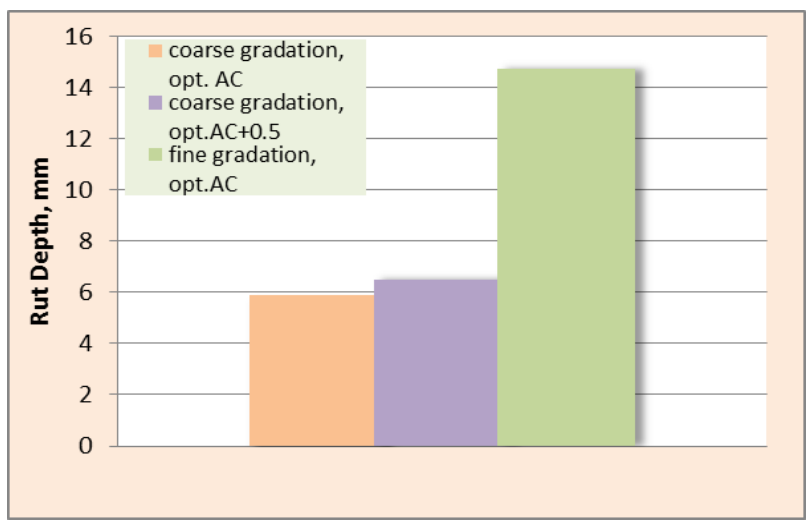

Fig.12. Effect of asphalt content of modified mixture on permanent deformation

\subsection{Effect of aggregate gradation}

Aggregate is present as a major portion of asphalt concrete mixture. It is found that researchers have come to different conclusions with regard to the effect of aggregate gradation on resistance to permanent deformation of asphalt mixtures.

Two gradations of aggregate that are typically used to produce hot mix asphalt in Iraq were used in this research. They are: coarse and fine gradation, both of 
them passing below the restricted zone (on the Superpave gradation chart). Figure (13) shows the results showed effect of aggregate gradation of mixture on permanent deformation; it concluded that rutting resistance of asphalt paving mixes is affected by the mix gradation of aggregate. Coarser gradation had higher resistance to rutting from fine gradation of aggregate by 65.6 percent as shown in Figure (14).

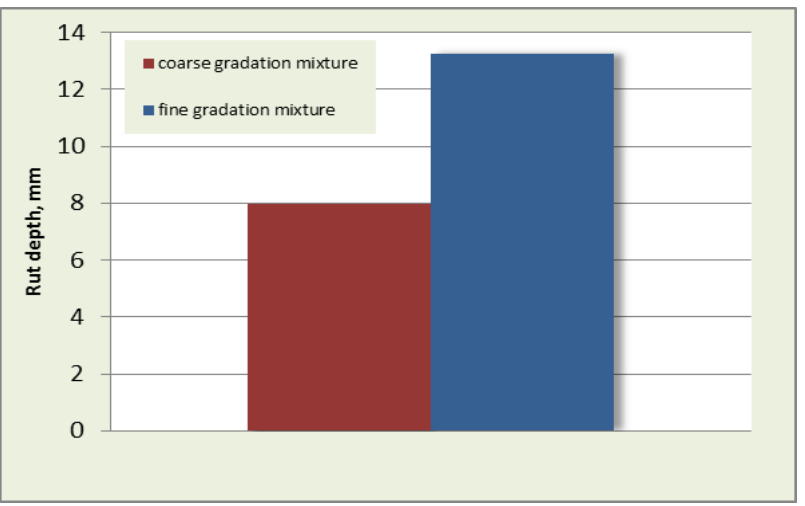

Fig.13. Effect of aggregate gradation of mixture on permanent deformation

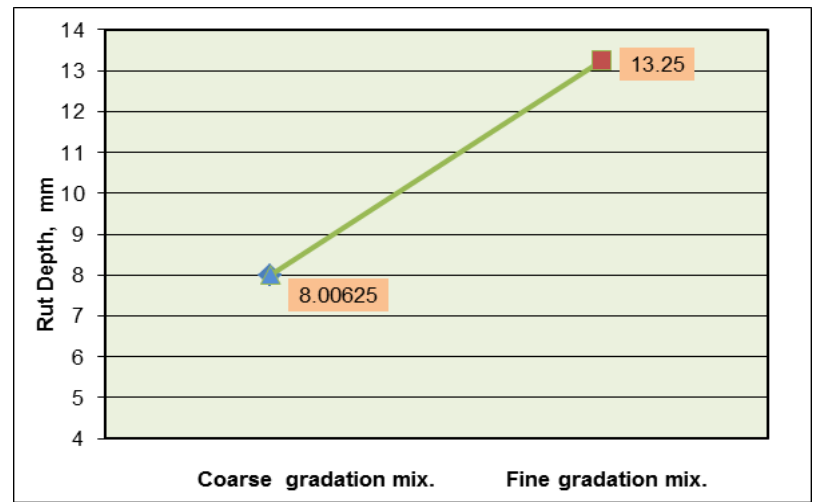

Fig. 14. Change in permanent deformation with aggregate gradations

\subsection{Effect of type of filler}

The resistance of asphalt mixture to permanent deformation is related to the stiffness of asphalt binder, mixture volumetrics, and the bonding interaction between asphalt binders and aggregate. Mineral filler is usually added into asphaltic mixture to stiffen asphalt binder and improve asphaltic mixture density and strength. These fillers are typically fine powders with particle sizes in the range of $0-100 \mu \mathrm{m}$, two types of filler were used in this research, there are: limestone and cement. However, the properties of mineral fillers of the compacted mixtures can influence on the permanent strain for conventional and modified mixtures as depicted in Figures (15) and (16). The percentage of change in Permanent Deformation is presented in Table (8). It can be observed that the rut depth (RD) decreases about 23.5 and 30.6 percent when the cement filler is used in asphaltic mixtures instead of limestone filler for coarse and fine gradation mixtures respectively. The effect of type of filler on the mixture rutting potential was more significant for the fine mixture than the coarse mixture.

Table 8. Permanent deformation change with type of filler

\begin{tabular}{|c|c|}
\hline Rut Depth, mm & $\begin{array}{c}\text { Effect of Type of Filler } \\
\text { From (lime) to (cement), \% }\end{array}$ \\
\hline Coarse gradation & -23.5 \\
\hline Fine gradation & -30.6 \\
\hline
\end{tabular}

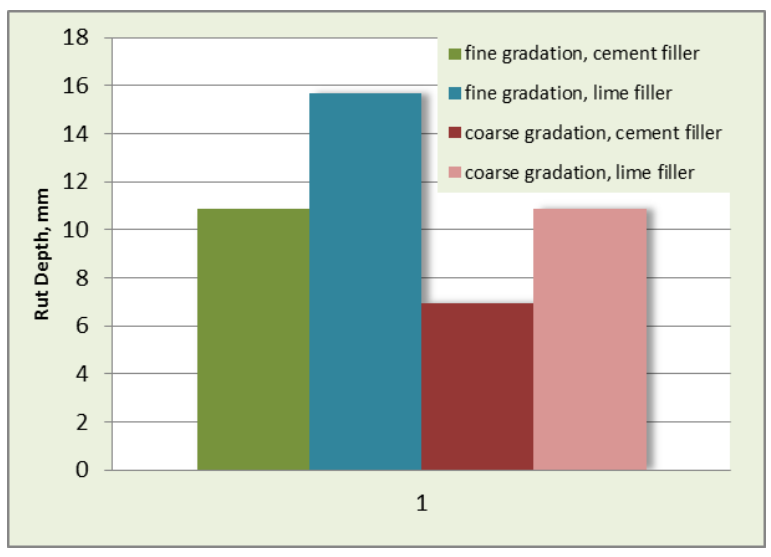

Fig. 15. Effect of type of filler in mixture on permanent deformation

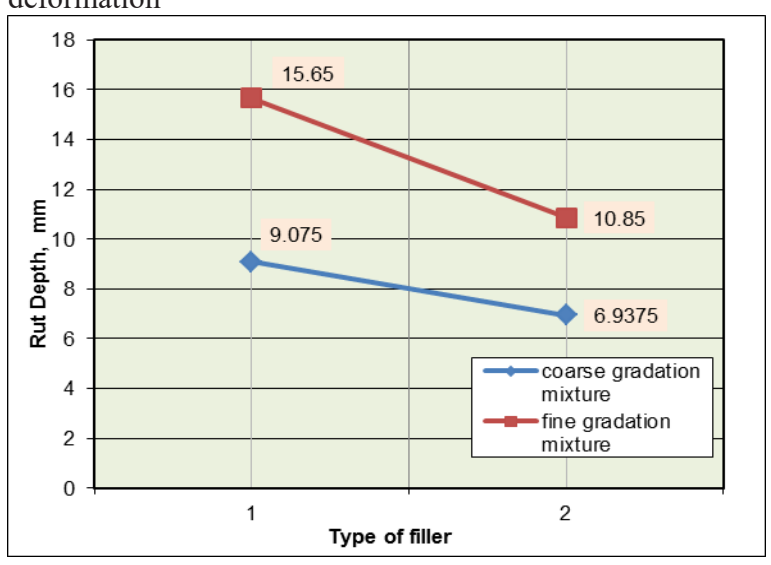

Fig. 16. Change in permanent deformation with type of filler in mixture

\subsection{Effect of steel reinforcement}

Reinforcing is a structural measure of increasing strength against the variety of stresses and improving its strength characteristics. Several studies have been conducted in order to investigate the effect of reinforcement materials on asphalt pavements. In this research one type of reinforcement material is used to improve the strength properties of asphaltic concrete mixtures and reduce the shear strain.

In this research an improvement was observed in rutting behavior of metal reinforced samples compared 
with those without reinforcement. Moreover, samples containing expanded mesh reinforcement performed better against rutting. It was observed that the permanent deformation of the asphalt concrete pavement is decreased in the presence of metal reinforcement; Figure (17).

The reinforcement stiffness and its interlocking with the asphalt concrete contribute to the restraining effect. The developed strains in the reinforcement around the vicinity of the loading area manifested the restraining effect of reinforcement. Moreover, there was a reduction in settlement over the loading area of reinforced samples compared with that of those without reinforcement.

As a result, when reinforced samples are achieved compared to those of control ones, it appears that permanent deformation of asphaltic pavements decreases by 41.1 and 19.7 percent for coarse and fine aggregate gradation respectively as shown in Figure (18).

Table 9. The Percentage of change in permanent deformation with steel reinforcement

\begin{tabular}{|c|c|c|}
\hline \multirow{2}{*}{ Variable } & \multicolumn{2}{|c|}{ Effect of Steel Reinforcement, (\%) } \\
\cline { 2 - 3 } & Coarse gradation & Fine gradation \\
\hline $\begin{array}{c}\text { Rut Depth } \\
\text { mm }\end{array}$ & -41.1 & -19.7 \\
\hline
\end{tabular}

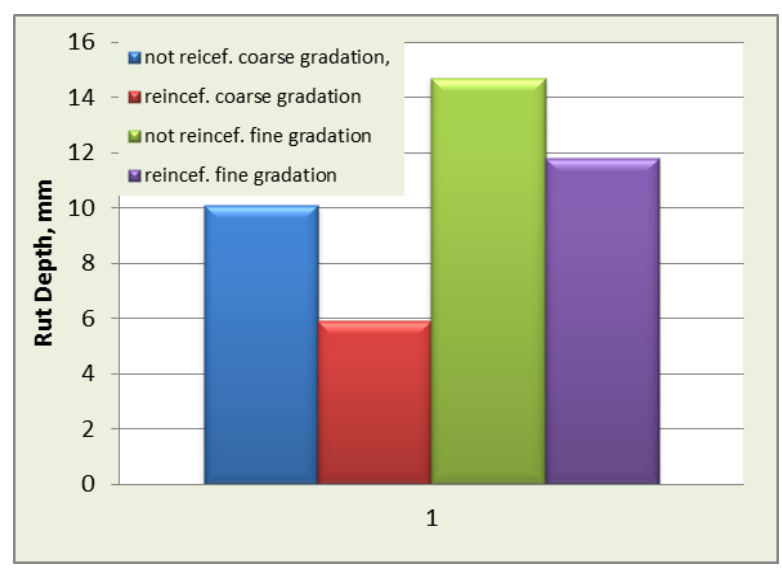

Fig. 17. Effect of steel reinforcement on permanent deformation of mixtures

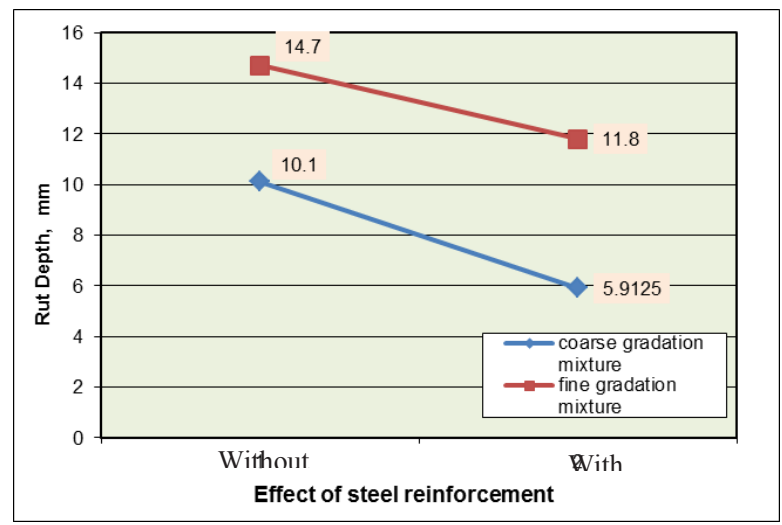

Fig. 18. Change in permanent deformation with steel reinforcement

\subsection{Effect of SBS polymer additive}

It was noted that the mixes with the polymer-modified binder were more difficult to mix and compact during the preparation of the samples. Any cooling of the mix greatly increases the viscosity of the asphalt and the stiffness of the mix.

In this research, the addition of additive (SBS) polymer tends to improve the mix properties. In Superpave mix design, the results showed that rutting performance of the asphaltic samples has improved for the polymer modified cases.

The percentage of change in permanent deformation with Polymers Content was shown in Table (10). It can be observed that the permanent displacement (RD) decreases about 37.22 and 29.5 percent when SBS polymer is used for coarse and fine gradation mixtures, respectively, as shown in Figures (19) and (20).

Based on the above evaluation, the use of asphalt modified by SBS polymer gives the wearing course better rutting resistance than the fine gradation of the same asphalt performance grade.

At the testing temperature of $40^{\circ} \mathrm{C} \pm 5$, the asphaltic mixtures appeared to maintain stiffness levels. However, it should be noted that when SBS polymer modifier is used, the HMA become stiffer at the high testing temperature. It can be concluded that SBS polymermodified binder made the polymer modified mixtures stiffer than control mixes with unmodified asphalt binder at high temperature.

Table 10. Percentage of change in permanent deformation with polymers content

\begin{tabular}{|c|c|c|}
\hline \multirow{2}{*}{ Variable } & \multicolumn{2}{|c|}{ Effect of Polymer (SBS) Content (\%) } \\
\cline { 2 - 3 } & Coarse gradation & Fine gradation \\
\hline $\begin{array}{c}\text { Rut Depth } \\
\text { mm }\end{array}$ & -37.22 & -29.5 \\
\hline
\end{tabular}




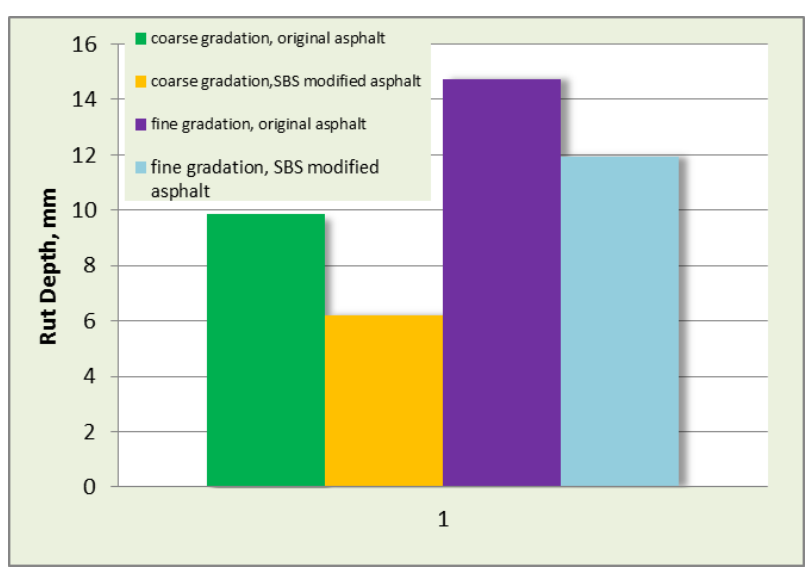

Fig. 19. Effect of SBS polymer on permanent deformation of mixtures

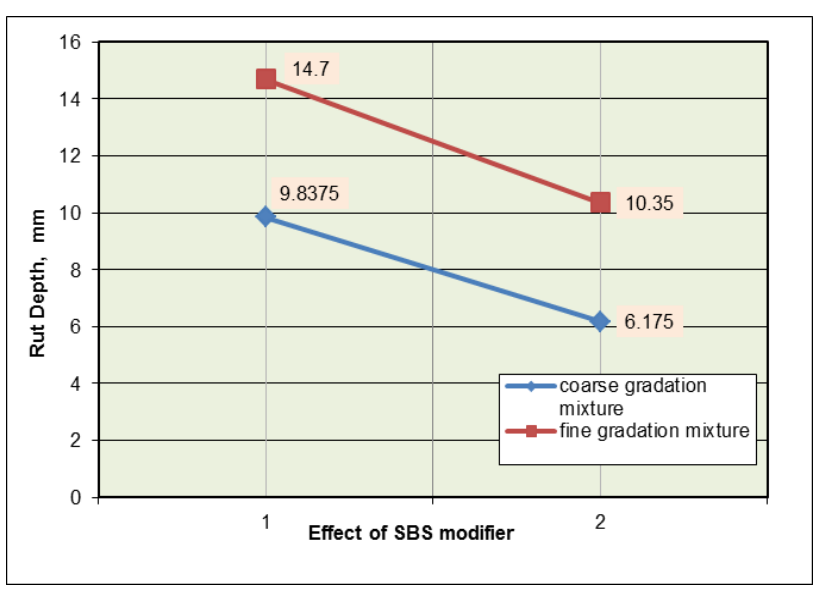

Fig. 20. Change in permanent deformation with SBS polymer modifier

\section{Conclusions}

Considering all results of laboratory tests and analysis, the following conclusions are presented:

- Wheel-track permanent deformation results for asphaltic wearing course mixes indicate that increasing of compaction temperature from 110 to $150{ }^{\circ} \mathrm{C}$ will decrease the permanent deformation by 20.5 and 15.6 percent for coarse and fine gradation control asphalt mixtures, respectively. While the rut depth (RD) decrease about 21.3 percent when the compaction temperature increases from 110 to $150{ }^{\circ} \mathrm{C}$ for coarse gradation SBS modified asphalt mixtures.

- The permanent deformation is increased with the increases in asphalt content from optimum AC to opt. +0.5 percent asphalt content for conventional and modified asphaltic mixtures. For (RD) value, it can be found that it increases about 10.6 percent when asphalt content increases from 4.6 to 5.1 percent for conventional coarse asphalt mixture, while it increase about 8 percent when asphalt content from 4.9 to 5.4 percent for SBS modified asphalt mixture.

- Wheel-track permanent deformation results showed effect of aggregate gradation of mixture on permanent deformation, it concluded that rutting resistance of asphalt paving mixes is affected by the mix gradation of aggregate. Coarser gradation had higher resistance to rutting from fine gradation of aggregate by 65.6 percent for conventional asphalt mixtures.

- The permanent deformation decreases about 23.5 and 30.6 percent when the cement filler is used in asphaltic mixtures instead of limestone filler for coarse and fine gradation mixtures, respectively. The effect of type of filler on the mixture rutting potential was more significant for the fine mixture than the coarse mixture.

- The permanent displacement (RD) decreases about 37.22 and 29.5 percent when SBS polymer is used for coarse and fine gradation mixtures respectively. Based on the results, the use of an asphalt modified by SBS polymers gives the coarse wearing course better rutting resistance than the fine gradation of the same asphalt performance grade.

- The permanent deformation decreases when reinforced samples are achieved compared to those of control ones, it appears that permanent deformation of asphaltic pavements decreases by 41.1 and 19.7 percent for coarse and fine aggregate gradations respectively.

- The impact of factors on tensile strength ratio TSR and moisture susceptibility is assessed. It is discovered that utilizing cement as filler, TSR is increased by ( 5 and 3.5) percent for coarse and fine gradations at optimum design of asphalt binder content, while TSR increases by 2.07 and 2.5 percent for coarse and fine gradations at modified optimum design of asphalt binder content.

- Also when utilizing the SBS polymer modifier for coarse and fine gradations, it can be presumed that TSR is increased by 6.1 and 4.5 percent at optimum design asphalt of binder content for lime filler, respectively, while TSR increased by 3.2 and 3.4 percent for coarse and fine gradations at modified optimum design of asphalt binder content for cement filler, respectively.

\section{References}

1. H. M. Hamdou, N. G. Ahmed, Z. I. Qasim, IMS/7 International Conference on Advances In Engineering Materials, UAE, 2014.

2. Y.Huang, Pavement Analysis and Design, Prentice Hall, Englewood Cliffs, New Jersey, USA. (1993).

3. I. Ishai, and J. Craus, "Transportation Research Record 1530, National Research Council, Washington, D.C., pp. 75-86 (1996).

4. Z. I. Qasim, A.S. Abbas, Z. I., Qasim, NJESl, 2017.

5. General Specification for Roads and Bridges, SCRB/ R9, Iraq (2003).

6. AASHTO Guide for Design of Pavement Structures, The American Association of State Highway and Transportation Officials, Washington, D. C., USA. (2010).

7. M. Y. Fattah, K. H. Al Helo, Z. I. Qasim, JRMPD, (2015). 
8. Z. I. Qasim, A.H. Abed, The 2nd International Conference on Buildings, Construction and Environmental Engineering (BCEE2), Lebanon, (2015).

9. European Standards EN 12697: Bituminous mixtures Test methods for hot mix asphalt, CEN/TC 227, (2005). 